\title{
Consumo e desempenho de novilhos alimentados com borra de soja em confinamento
}

\section{Intake and performance of steers fed with soybean dreg in confinement}

\begin{abstract}
Álisson Marian Callegaro ${ }^{1 *}$; Dari Celestino Alves Filho²; Ivan Luiz Brondani³ Magali Floriano da Silveira ${ }^{4}$; Luiz Angelo Damian Pizzuti ${ }^{5}$; Perla Cordeiro de Paula ${ }^{6}$; Viviane Santos da Silva ${ }^{6}$; Leandro da Silva Freitas ${ }^{7}$; Luciane Rumpel Segabinazzi ${ }^{8}$; Diego Soares Machado ${ }^{6}$; Ana Paula Machado Martini ${ }^{6}$; Leonel da Silva Rodrigues ${ }^{9}$
\end{abstract}

\section{Resumo}

O estudo foi desenvolvido com objetivo de avaliar a viabilidade de utilização da borra de soja na terminação de novilhos confinados, com idade e peso médio inicial de 20 meses e $328,3 \mathrm{~kg}$, respectivamente. Cada tratamento foi composto por seis animais experimentais, os quais receberam dieta com relação volumoso: concentrado, 40:60 (base na matéria seca), sendo o volumoso, a silagem de milho e concentrado a base de casca, farelo e borra de soja, milho, cloreto de sódio e calcário calcítico. Os novilhos foram distribuídos nos tratamentos: 00; 30;60; 90 e 120 g de borra de soja por $\mathrm{kg}$, na forma como o alimento foi oferecido, os quais continham 29,0;47,3;66,7;86,8 e 106,8 g de extrato etéreo por kg de matéria seca, respectivamente. $\mathrm{O}$ consumo de matéria seca foi similar $(\mathrm{P}>0,05)$ entre os novilhos dos tratamentos estudados com média de $9,71 \mathrm{~kg} \mathrm{dia}^{-1}$. Do mesmo modo, não foram observadas diferenças $(\mathrm{P}>0,05)$ no consumo de proteína bruta pelos animais entre os tratamentos, com média de $1,36 \mathrm{~kg} \mathrm{dia}^{-1}$. Porém, houve diferença no consumo de extrato etéreo e fibras em detergente neutro e ácido, as quais tiveram comportamento linear com o aumento da inclusão de borra na ração ( $\mathrm{CEE}=0,305+0,0061 \mathrm{BS} ; \mathrm{CFDN}=5,71-0,011 \mathrm{BS} ; \mathrm{CFDA}=3,89-0,008 \mathrm{BS}$ em kg dia ${ }^{-1}$, respectivamente). O desempenho dos novilhos foi semelhante $(\mathrm{P}>0,05)$ entre os tratamentos, sendo o ganho médio diário de $1,542 \mathrm{~kg}$, a conversão alimentar de $6,35 \mathrm{~kg}$ de MS kg-1 ganho de peso e o peso de abate de 457,95 kg. O uso da borra de soja até o limite de $120 \mathrm{~g}$ na dieta de bovinos confinados é viável.

Palavras-chave: Casca de soja, consumo de fibra em detergente neutro, extrato etéreo, ganho médio diário

\footnotetext{
${ }^{1}$ Zootecnista e Médico Veterinário, Dr., Discente do Programa Especial de Graduação de Formação de Professores para a Educação Profissional, Universidade Federal de Santa Maria, UFSM, Santa Maria, RS. E-mail: mcalisson@hotmail.com

${ }^{2}$ Eng $^{\mathrm{o}}$ Agr $^{\mathrm{o}}$, Prof. Dr., Dept ${ }^{\mathrm{o}}$ de Zootecnia, Santa Maria, RS. E-mail: darialvesfilho@hotmail.com

3 Zootecnsita, Prof. Dr., Dept ${ }^{\circ}$ de Zootecnia, UFSM, Santa Maria, RS. E-mail: ivanbrondani@gmail.com

${ }^{4}$ Zootecnsita, Prof ${ }^{a}$ Dra ${ }^{\text {a }}$ Coordenação de Zootecnia, Universidade Tecnológica Federal do Paraná, UTFPR, Dois Vizinhos, PR. E-mail: mg_flor@yahoo.com.br

${ }^{5}$ Zootecnista, Prof. Dr., Zootecnia do Instituto Federal do Rio Grande do Sul, Câmpus Bento Gonçalves, IFRS, Bento Gonçalves, RS. E-mail: pizzuti@zootecnista.com.br

${ }^{6}$ Zootecnistas, Mestres, Discentes do Programa de Pós Graduação em Zootecnia, Universidade Federal de Santa Maria, UFSM, Santa Maria, RS. E-mail: perla.zoot@gmail.com; stsvivi@gmail.com; dhiego_machado@hotmail.com; anapaulamartini@ zootecnista.com.br

${ }^{7}$ Zootecnista, Prof. Dr., Dept ${ }^{\circ}$ de Direção de Ensino, Instituto Federal do Farroupilha - Câmpus Alegrete, IFF, Alegrete, RS. E-mail: freitaszoot@hotmail.com

${ }^{8}$ Zootecnsita, Prof ${ }^{a}$ Dr $^{\mathrm{a}}$, Dept ${ }^{\mathrm{o}}$ de Zootecnia, Universidade Federal do Pampa, Câmpus Dom Pedrito, UNIPAMPA, Dom Pedrito, RS. E-mail: luzoot@hotmail.com

9 Eng $^{\circ}$ Agr $^{\circ}$, Discente do Programa de Pós Graduação em Zootecnia, UFSM, Santa Maria, RS. E-mail: rodrigues_leonel@hotmail.com

* Autor para correspondência
} 


\begin{abstract}
This study was designed to evaluate the feasibility of using soybean dreg in finishing of confined steers, with age and initial body weight of 20 months and $328.3 \mathrm{~kg}$, respectively. Each treatment consisted of six experimental animals, which were fed with forage: concentrate ratio, 40:60 (dry matter basis), being bulky corn silage and concentrate based of bark, chaff and soybean dreg, corn, sodium chloride and calcium limestone. The steers were distributed in the treatments: 00, 30, 60, 90 and $120 \mathrm{~g}$ of soybean dreg per $\mathrm{kg}$ of dry matter in the diet, which contained 29.0, 47.3, 66.7, 86.8 and $106.8 \mathrm{~g}$ of ether extract, respectively. The dry matter intake was similar $(\mathrm{P}>0.05)$ among the studied treatments with an average of $9.71 \mathrm{~kg} \mathrm{day}^{-1}$. Similarly, no differences were observed $(\mathrm{P}>0.05)$ in crude protein intake with an average of $1.36 \mathrm{~kg} \mathrm{day}^{-1}$. However, there were differences in the consumption of ether extract and neutral and acid detergent fibre, which had behavior with the increase in the inclusion of dreg in the diet (CEE=0,305+0,0061SD; $\mathrm{CFDN}=5.71-0,011 \mathrm{SD}$; $\mathrm{CFDA}=3.89-0.008 \mathrm{SD} \mathrm{kg} \mathrm{day}{ }^{-1}$, respectively). The performance of steers was similar $(\mathrm{P}>0.05)$ between treatments, being the average daily gain of $1.542 \mathrm{~kg}$, the fed conversion of $6.35 \mathrm{~kg} \mathrm{DM} \mathrm{kg}^{-1}$ weight gain and slaughter weight of $457.95 \mathrm{~kg}$. The use of soybean dreg until the limit of $120 \mathrm{~g}$ in the diet of confined cattle is feasible.
\end{abstract}

Key words: Soybean hull, neutral detergent fibre intake, ether extract, average daily gain

\section{Introdução}

Cada vez mais no Brasil é expressiva a terminação de bovinos em confinamento. Entre os fatores que motivam o uso deste sistema, pode-se citar o aumento das áreas produtoras de grãos nos últimos anos, diminuindo-se as áreas pastoris, o que torna o uso do confinamento uma opção por liberar áreas agricultáveis no período de plantio dos grãos. Todavia, o elo fraco do confinamento é o retorno econômico direto, onde normalmente a tomada de decisão do que fornecer no cocho é uma variável dependente de conciliar disponibilidade e o custo de matéria prima.

Diante do exposto, é habitual buscarem-se subprodutos agrícolas disponíveis no mercado que contemplem preço e composição bromatológica adequada para atender as exigências nutricionais de cada categoria e dessa forma não comprometer o tempo de terminação.

Entre os coprodutos produzidos, destacam-se os oriundos da cultura da soja. A utilização de farelo de soja e/ou casca de soja é relativamente vasta, contudo a resposta da utilização da borra de soja na alimentação de ruminantes é praticamente inexistente.

No processamento da soja origina-se o óleo bruto que passa por uma etapa denominada de degomagem, em que resultam o óleo degomado e a goma que após passar pela etapa de secagem se transforma em lecitina. Esse resíduo decorrente do processamento de soja chamado de borra corresponde a $0,04 \%$ dos resíduos sólidos gerados é obtido no fundo dos tanques de óleo bruto.

Este coderivado se caracteriza por apresentar em temperatura ambiente, estado físico pastoso e quando homogeneizado fica com consistência cremosa. Seu transporte é feito em caminhões tanque ou tonéis, o que dificulta seu manejo, porém encontra-se disponível no mercado a custo relativamente baixo, comparando-se aos demais ingredientes utilizados na alimentação animal. Por ser um derivado da soja (875,5 g extrato etéreo $\mathrm{kg}^{-1}$ de MS) caracteriza-se por apresentar alta densidade energética $(1931,1 \mathrm{~g}$ nutrientes digestíveis totais $\mathrm{kg}^{-1}$ de MS), permitindo assim que os bovinos ingiram menor quantidade de matéria seca para suprir suas necessidades.

Sendo assim, objetivou-se com o presente estudo avaliar a inclusão da borra de soja na dieta, por meio do desempenho de bovinos confinados.

\section{Material e Métodos}

O experimento foi conduzido no Laboratório de Bovinocultura de Corte do Departamento de 
Zootecnia da Universidade Federal de Santa Maria (UFSM), município de Santa Maria, localizado na depressão central do Rio Grande do Sul.

No experimento foram utilizados 30 bovinos machos castrados, Charolês $\mathrm{x}$ Nelore com idade e peso vivo inicial de 20 meses e $328,3 \mathrm{~kg}$, respectivamente. Os novilhos foram provenientes do rebanho experimental do Laboratório de Bovinocultura de Corte, contemporâneos e recriados em mesmo sistema de alimentação até o início da terminação, e alojados em baias individuais de 12 $\mathrm{m}^{2}$, com piso de alvenaria, providas de bebedouro e comedouro individualizado.

Os tratamentos foram: 00; 30; 60; 90 e $120 \mathrm{~g}$ $\mathrm{kg}^{-1}$ de inclusão de borra de soja na dieta, na forma como o alimento foi oferecido, as quais continham, respectivamente, 29,$0 ; 47,3 ; 66,7 ; 86,8$ e 106,8 g $\mathrm{kg}^{-1}$ de extrato etéreo (EE) na dieta em base seca, tendo como base a composição dos componentes bromatológicos dos alimentos utilizados na dieta (Tabela 1). O período de adaptação dos animais às dietas, às instalações e ao manejo alimentar foi de 15 dias e o período experimental totalizou 84 dias.

Durante o experimento todos os animais receberam dieta com relação volumoso: concentrado de 40:60 (base da matéria seca), calculada conforme recomendações do NRC (2001), para atender as exigências nutricionais dos animais (Tabela 2), objetivando ganho de peso diário de $1,2 \mathrm{~kg}$ animal ${ }^{-1}$, estimando-se o consumo de matéria seca em $2,5 \mathrm{~kg}$ de matéria seca $100 \mathrm{~kg}^{-1}$ de peso vivo.

Tabela 1. Composição bromatológica dos ingredientes das dietas.

\begin{tabular}{|c|c|c|c|c|c|c|c|}
\hline \multirow{2}{*}{$\begin{array}{l}\text { Teores, } \\
\text { g kg }^{-1} \text { de MS }\end{array}$} & \multicolumn{7}{|c|}{ Ingredientes das dietas } \\
\hline & $\begin{array}{l}\text { Silagem de } \\
\text { milho }\end{array}$ & $\begin{array}{c}\text { Casca de } \\
\text { soja }\end{array}$ & $\begin{array}{c}\text { Farelo de } \\
\text { soja }\end{array}$ & Milho & $\begin{array}{l}\text { Borra de } \\
\text { soja }\end{array}$ & $\begin{array}{l}\text { Calcário } \\
\text { calcítico }\end{array}$ & $\begin{array}{l}\text { Cloreto de } \\
\text { sódio }\end{array}$ \\
\hline MS * & 319,2 & 881,0 & 871,3 & 867,1 & 635,0 & 1000,0 & 1000,0 \\
\hline MO & 913,8 & 943,2 & 932,8 & 984,1 & 929,1 & 736,7 & - \\
\hline MM & 86,3 & 56,8 & 67,2 & 15,8 & 70,9 & 363,3 & 1000,0 \\
\hline PB & 49,1 & 116,4 & 522,4 & 98,8 & 53,5 & - & - \\
\hline $\mathrm{EE}$ & 32,7 & 25,7 & 35,0 & 59,2 & 875,5 & - & - \\
\hline FDN & 589,9 & 653,4 & 183,0 & 149,9 & - & - & - \\
\hline FDA & 317,1 & 497,4 & 124,4 & 29,5 & - & - & - \\
\hline NIDN & 1,8 & 7,2 & 23,4 & 1,96 & - & - & - \\
\hline NIDA & 0,7 & 1,7 & 8,6 & 0,79 & - & - & - \\
\hline LDA & 46,5 & 21,8 & 41,0 & 12,6 & - & - & - \\
\hline NDT & 598,7 & 658,6 & 786,7 & 887,1 & 193,1 & - & - \\
\hline
\end{tabular}

* $\mathrm{g} \mathrm{kg}^{-1}$ de matéria natural; $\mathrm{MS}=$ matéria seca; $\mathrm{MO}=$ matéria orgânica; $\mathrm{MM}=$ matéria mineral; $\mathrm{PB}=$ proteína bruta; $\mathrm{EE}=$ extrato etéreo; FDN= fibra em detergente neutro; FDA= fibra em detergente ácido; NIDN= nitrogênio insolúvel em detergente neutro; $\mathrm{NIDA}=$ nitrogênio insolúvel em detergente ácido; $\mathrm{LDA}=$ lignina em detergente ácido; NDT= nutrientes digestíveis totais.

Fonte: Elaboração dos autores

$\mathrm{O}$ volumoso fornecido aos animais foi silagem de milho e o concentrado composto por casca de soja, farelo de soja, milho, borra de soja, cloreto de sódio e calcário calcítico.

A alimentação dos animais foi "ad libitum", fornecida em duas refeições diárias (08h30min e $14 \mathrm{~h} 00 \mathrm{~min}$ ), sendo que as sobras foram pesadas e ajustadas diariamente de modo que oscilassem entre 50 e 80 gramas por $\mathrm{kg}$ de alimento ofertado.

À medida que era preparada uma nova partida 
de concentrado, coletavam-se amostras dos ingredientes. As amostras de borra de soja foram armazenadas em freezer a temperatura de $-18^{\circ} \mathrm{C}$, e posteriormente encaminhadas para análise laboratorial. Semanalmente foram coletadas amostras de sobras e de silagem, que foram présecas em estufa dotada com circulação forçada de ar a $55^{\circ} \mathrm{C}$, durante 72 duas horas para determinação de matéria parcialmente seca. Após pré-secagem as amostras foram moídas em moinho tipo Willey, com peneiras com crivo de $1 \mathrm{~mm}$ de diâmetro.

O teor de nutrientes digestíveis totais (NDT) foi calculado segundo a metodologia de Weiss, Conrad e Pierre (1992) e a energia digestível (ED) com base no NRC (2001), considerando que $1 \mathrm{~kg}$ de NDT equivale a 4,4 Mcal de energia digestível.

Tabela 2. Ingredientes volumoso na base seca e concentrado na forma ofertada e composição bromatológica das dietas experimentais (base da matéria seca).

\begin{tabular}{lrrrrr}
\hline \multirow{2}{*}{\multicolumn{1}{c}{ Ingredientes $\left(\mathrm{g} \mathrm{kg}^{-1}\right)$}} & \multicolumn{5}{c}{ Níveis de inclusão de borra de soja* } \\
\cline { 2 - 5 } & \multicolumn{1}{c}{00} & \multicolumn{1}{c}{30} & 60 & \multicolumn{1}{c}{90} & \multicolumn{1}{c}{120} \\
\hline Silagem de milho & 384,5 & 387,7 & 390,9 & 394,2 & 398,0 \\
Casca de soja & 486,3 & 445,2 & 405,0 & 355,0 & 301,0 \\
Farelo de soja & 113,9 & 122,5 & 129,1 & 139,3 & 144,5 \\
Borra de soja & - & 29,4 & 59,7 & 89,7 & 118,3 \\
Milho & - & - & - & 0,61 & 2,26 \\
Calcário calcítico & 6,2 & 6,1 & 6,1 & 6,7 & 6,6 \\
Cloreto de sódio & 9,2 & 9,2 & 9,1 & 9,1 & 9,0 \\
\hline & Composição bromatológica (g kg-1 de MS) & & \\
\hline Matéria Seca ** & 665,7 & 656,5 & 647,2 & 637,9 & 628,6 \\
Proteína Bruta & 134,1 & 136,7 & 138,5 & 141,7 & 142,7 \\
Extrato Etéreo & 29,0 & 47,3 & 66,7 & 86,8 & 106,8 \\
Matéria Mineral & 58,7 & 58,6 & 58,4 & 58,3 & 57,3 \\
Fibra Detergente Neutro & 564,6 & 545,5 & 526,4 & 501,4 & 473,9 \\
Fibra Detergente Ácido & 377,4 & 362,3 & 347,2 & 327,0 & 304,0 \\
Lignina & 33,0 & 32,8 & 32,6 & 32,3 & 31,9 \\
Nutrientes Digestíveis Totais & 638,4 & 668,5 & 696,5 & 728,2 & 761,8 \\
Energia Digestível, Mcal kg-1 & 2,80 & 2,93 & 3,06 & 3,20 & 3,35 \\
\hline
\end{tabular}

* Na forma como o alimento é oferecido, $\mathrm{g} \mathrm{kg}^{-1} ; * * \mathrm{~g} \mathrm{~kg}^{-1}$ de matéria natural; $\mathrm{MS}=$ matéria seca

Fonte: Elaboração dos autores

As pesagens dos animais foram realizadas no início e no final do período experimental, precedidas de jejum de sólidos e líquidos de 14 horas, e junto a estas foram atribuídos escore de condição corporal (ECC), segundo Lowaman et al. (1973).

O delineamento utilizado foi o inteiramente casualizado, com cinco tratamentos e seis repetições, sendo o animal a unidade experimental. As variáveis foram testadas quanto a normalidade pelo teste de Shapiro-Wilk. Os dados foram submetidos à análise de variância pelo teste $\mathrm{F}$, pelo procedimento PROC GLM e as médias comparadas pelo teste " $\mathrm{t}$ " em 5\% de significância.

O modelo matemático correspondeu ao modelo geral do delineamento inteiramente casualizado:

$$
\mathrm{Y}_{\mathrm{ij}}=\mu+\tau_{\mathrm{i}}+\varepsilon_{\mathrm{ij}}
$$

Pelo modelo, $\mathrm{Y}_{\mathrm{ij}}$ representa a variável dependente; $\mu$ é a média de todas as observações; $\tau_{i}$ corresponde ao efeito dos tratamentos; $\varepsilon_{\mathrm{ij}}$ corresponde ao erro 
experimental residual.

Já para o estudo da regressão polinomial, pelo comando PROC RSREG foi utilizado o seguinte modelo:

$$
\mathrm{Y}_{\mathrm{ijk}}=\beta_{0}+\beta_{1} \mathrm{X}_{\mathrm{i}}+\beta_{2} \mathrm{X}_{\mathrm{i}}^{2}+\beta_{3} \mathrm{X}_{\mathrm{i}}^{3}+\alpha_{\mathrm{ijk}}+\varepsilon_{\mathrm{ijk}}
$$

Pelo modelo, $\mathrm{Y}_{\mathrm{ijk}}$ representa a variável dependente; $\beta$ 's correspondem aos coeficientes de regressão; $X_{\mathrm{ijk}}$ representa o teor de inclusão de borra de soja; $\alpha_{\mathrm{ijk}}$ corresponde aos desvios da regressão; e $\varepsilon_{\mathrm{ijk}}$ o erro aleatório residual.

O grau do polinômio adotado para cada variável foi dado pelo critério de significância pelo teste $F$ e pelo coeficiente de determinação, quando houve significância para cada grau de polinômio.
Foram realizadas análises de falta de ajuste (lack-of-fit) dos modelos de regressão escolhidos e análise de resíduos para detecção da existência de outliers, não sendo detectadas observações que fossem consideradas anormais nesta última análise. Os dados foram analisados com auxilio do pacote estatístico SAS (2001).

\section{Resultados e Discussão}

O aumento da inclusão de borra de soja nas rações não influenciou $(\mathrm{P}>0,05)$ o consumo de matéria seca pelos animais, expresso em percentagem do peso vivo ou por unidade de tamanho metabólico (Tabela 3).

Tabela 3. Médias, coeficientes de variação e probabilidades dos consumos diários de matéria seca e proteína bruta por dia e eficiência protéica na dieta de novilhos submetidos a níveis de inclusão de borra de soja

\begin{tabular}{|c|c|c|c|c|c|c|c|}
\hline \multirow{2}{*}{ Variáveis } & \multicolumn{5}{|c|}{ Níveis de inclusão de borra de soja* } & \multirow{2}{*}{$\mathrm{CV}$} & \multirow{2}{*}{$\mathrm{P}>\mathrm{F}$} \\
\hline & 00 & 30 & 60 & 90 & 120 & & \\
\hline CMS, kg dia ${ }^{-1}$ & 10,30 & 9,65 & 9,68 & 9,92 & 9,01 & 14,18 & 0,5998 \\
\hline CMSTM, $\mathrm{g} \mathrm{kg}^{-1}$ peso vivo 0,75 & 116,52 & 110,08 & 108,68 & 112,36 & 103,93 & 6,40 & 0,0681 \\
\hline CMSPV, kg $100 \mathrm{~kg}^{-1}$ peso vivo & 2,62 & 2,48 & 2,44 & 2,53 & 2,35 & 6,03 & 0,0673 \\
\hline $\mathrm{CPB}, \mathrm{kg} \mathrm{dia}^{-1}$ & 1,406 & 1,349 & 1,353 & 1,420 & 1,294 & 8,49 & 0,3754 \\
\hline CPBTM, $\mathrm{g} \mathrm{kg}^{-1}$ peso vivo ${ }^{0,75}$ & 15,90 & 15,38 & 15,18 & 16,07 & 14,93 & 6,32 & 0,2547 \\
\hline CPBPV, $\mathrm{kg} 100 \mathrm{~kg}^{-1}$ peso vivo & 0,357 & 0,347 & 0,341 & 0,362 & 0,338 & 5,86 & 0,2377 \\
\hline $\mathrm{EPB}, \mathrm{kg}$ peso vivo $\mathrm{kg}^{-1} \mathrm{~PB}$ & 1,136 & 1,161 & 1,181 & 1,055 & 1,140 & 8,92 & 0,2911 \\
\hline
\end{tabular}

* Na forma como o alimento é oferecido, $\mathrm{g} \mathrm{kg}^{-1}$

$\mathrm{CMSTM}=$ consumo de matéria seca por unidade de tamanho metabólico; CMSPV= consumo de matéria seca em percentagem do peso vivo; $\mathrm{CPB}=$ consumo de proteína bruta $\mathrm{CPBTM}=$ consumo de proteína bruta por unidade de tamanho metabólico; $\mathrm{CPBPV}=$ consumo de proteína bruta em percentagem do peso vivo; $\mathrm{EPB}=$ eficiência protéica

Fonte: Elaboração dos autores

Shain et al. (1993) ao substituírem milho (250, 500,750 e $1000 \mathrm{~g} \mathrm{k}^{-1} \mathrm{~g}$ de MS) e casca de soja (250, 500 e $750 \mathrm{~g} \mathrm{~kg}^{-1}$ de MS) por uma mistura composta de lecitina, borra de soja e casca de soja na dieta de novilhos de corte, não observaram diferença no consumo de matéria seca $\left(9 \mathrm{~kg}\right.$ dia $\left.^{-1}\right)$. Nesta pesquisa, o consumo de matéria seca $\left(9,71 \mathrm{~kg}\right.$ dia ${ }^{-}$ $\left.{ }^{1}\right)$ foi semelhante ao obtido por Shain et al. (1993). Entretanto Abel-Caines et al. (1998) verificaram maior consumo de matéria seca para vacas leiteiras alimentadas com $120 \mathrm{~g} \mathrm{~kg}^{-1}$ de MS de mistura de casca de soja, lecitina e borra de soja $\left(27,1 \mathrm{~kg} \mathrm{dia}^{-1}\right)$ em relação a dieta controle, com alto teor de amido $\left(24,1 \mathrm{~kg} \mathrm{dia}^{-1}\right)$. O resultado do consumo de matéria seca no presente trabalho $\left(2,48 \mathrm{~kg} 100 \mathrm{~kg}^{-1}\right.$ de PV) foi inferior ao encontrado por Abel-Caines et al. (1998), que obtiveram 4,5 kg por $100 \mathrm{~kg}$ de peso vivo. 
Presume-se com isso, que o aumento dos níveis de inclusão de borra de soja não alterou a palatabilidade da dieta, pois os resultados foram semelhantes aos obtidos por Shain et al. (1993) e Abel-Caines et al. (1998).

Segundo Van Soest (1994) os bovinos consomem até atingir a saciedade, de modo que em dietas com maior densidade energética consomem menos alimentos para atingir suas necessidades. Entretanto, isso nem sempre ocorre, muitas vezes em dietas com alto teor energético, o consumo de energia digestível diminui, em função da falta de fibra efetiva no concentrado, contribuindo para diminuição da ruminação e do aumento do potencial de acidose ruminal (VAN SOEST, 1994).

Apesar do aumento na inclusão de borra de soja, a participação do volumoso na dieta provavelmente forneceu adequado teor de fibra efetiva, favorecendo com isso, a ruminação e o controle do $\mathrm{pH}$ ruminal, permitindo com que a hipotética diminuição no consumo induzida pela borra fosse compensada, consequentemente, não alterando o consumo de matéria seca (Tabela 3 ) e energia digestível (Tabela 4).

Tabela 4. Médias, coeficientes de variação e probabilidades dos consumos diários de extrato etéreo e de energia digestível, eficiência lipídica e de energia digestível na dieta de novilhos submetidos a níveis de inclusão de borra de soja.

\begin{tabular}{|c|c|c|c|c|c|c|c|}
\hline \multirow{2}{*}{ Variáveis } & \multicolumn{5}{|c|}{ Níveis de inclusão de borra de soja* } & \multirow{2}{*}{$\mathrm{CV}$} & \multirow{2}{*}{$\mathrm{P}>\mathrm{F}$} \\
\hline & 00 & 30 & 60 & 90 & 120 & & \\
\hline CEE, $\mathrm{kg} \mathrm{dia}^{-11}$ & 0,304 & 0,475 & 0,670 & 0,893 & 1,005 & 15,18 & 0,0001 \\
\hline CEETM, $\mathrm{g} \mathrm{kg}^{-1}$ peso vivo ${ }^{0,752}$ & 3,45 & 5,42 & 7,54 & 10,13 & 11,61 & 7,09 & 0,0001 \\
\hline CEEPV, $\mathrm{kg} 100 \mathrm{~kg}^{-1}$ peso vivo ${ }^{3}$ & 0,077 & 0,122 & 0,169 & 0,228 & 0,263 & 7,13 & 0,0001 \\
\hline 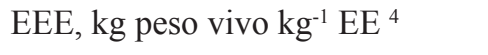 & 5,35 & 3,32 & 2,38 & 1,67 & 1,46 & 20,34 & 0,0001 \\
\hline CED, Mcal dia ${ }^{-1}$ & 28,98 & 28,48 & 29,93 & 32,10 & 30,56 & 8,57 & 0,1638 \\
\hline CEDTM, Mcal kg-1 peso vivo ${ }^{0,755}$ & 328,38 & 325,13 & 336,36 & 363,98 & 352,99 & 6,95 & 0,0074 \\
\hline CEDPV, kg $100 \mathrm{~kg}^{-1}$ peso vivo ${ }^{6}$ & 7,39 & 7,34 & 7,56 & 8,20 & 8,00 & 6,72 & 0,0040 \\
\hline EED, $\mathrm{kg}$ peso vivo $\mathrm{Mcal}^{-1} \mathrm{ED}^{7}$ & 0,055 & 0,054 & 0,053 & 0,046 & 0,048 & 10,72 & 0,0050 \\
\hline
\end{tabular}

* Na forma como o alimento é oferecido, $\mathrm{g} \mathrm{kg}^{-1}$

$\mathrm{CEE}=$ consumo de extrato etéreo; $\mathrm{CEETM}=$ consumo de extrato etéreo por unidade de tamanho metabólico;

$\mathrm{CEEPV}=$ consumo de extrato etéreo em percentagem do peso vivo; $\mathrm{EEE}=$ eficiência lipídica; $\mathrm{CED}=$ consumo de energia digestível; $\mathrm{CEDTM}=$ consumo de energia digestível por unidade de tamanho metabólico; $\mathrm{CEDPV}=$ consumo de energia digestivel em percentagem do peso vivo; $\mathrm{EED}=$ eficiência da energia digestível.

$\mathrm{BS}=$ teor de inclusão de borra de soja na dieta $\left(\mathrm{g} \mathrm{kg}^{-1}\right)$, na forma como o alimento é oferecido

${ }^{1} \mathrm{Y}=0,305+0,0061 \mathrm{BS} ; \mathrm{R}^{2}=0,8730 ;{ }^{2} \mathrm{Y}=3,42+0,070 \mathrm{BS} ; \mathrm{R}^{2}=0,9700 ;{ }^{3} \mathrm{Y}=0,0768+0,00160 \mathrm{BS} ; \mathrm{R}^{2}=0,9700 ;{ }^{4} \mathrm{Y}=4,72-$ $0,031 \mathrm{BS} ; \mathrm{R}^{2}=0,8506 ;{ }^{5} \mathrm{Y}=322,66+0,298 \mathrm{BS} ; \mathrm{R}^{2}=0,2292 ;{ }^{\circ} \mathrm{Y}=7,28+0,007 \mathrm{BS} ; \mathrm{R}^{2}=0,2603 ;{ }^{7} \mathrm{Y}=0,056-0,00007 \mathrm{BS} ; \mathrm{R}^{2}=$ 0,2495 .

Fonte: Elaboração d os autores.

Estas propriedades da casca de soja foram comprovadas, por Shain et al. (1993), ao alimentarem vacas leiteiras com $0 ; 60$ e $120 \mathrm{~g} \mathrm{~kg}^{-1}$ de mistura $(850,120$ e $30 \mathrm{~g}$ de casca, lecitina e borra de soja, respectivamente), perfazendo $35 ; 45$ e $53 \mathrm{~g}$ de extrato etéreo na dieta, respectivamente. Esses pesquisadores não observaram diferença na variação do $\mathrm{pH}$ ruminal (entre 6,0 e 6,5) até quatro horas após a alimentação. Desse modo, demonstraram que a casca de soja é um excelente meio de transporte de lecitina e borra na dieta.

A estas características da casca de soja, somase ainda o fato de ser um ingrediente com baixo teor de lignina e associado à grande proporção de 
fibra digestível, que lhe confere alta passagem pelo trato gastrintestinal. Acrescenta-se que, a maior participação da casca de soja na dieta permitiu que a borra ficasse bem distribuída e aderida às partículas desta, permitindo nesse contexto, o transporte desse ingrediente pelo trato digestivo.

Outro componente que atua no centro de saciedade é o teor de ácido graxo insaturado (AGI) que chega ao intestino delgado, pois segundo Obici et al. (2002), o aumento da concentração sérica de AGI ativa os receptores do centro da saciedade, localizados no hipotálamo, que inibem o apetite e o consumo dos alimentos. Dessa forma, apesar da borra de soja possuir 75,9\% de AGI, os níveis utilizados provavelmente não comprometeram a concentração sérica.

Embora, os níveis de borra de soja (106,8 g de extrato etéreo $\mathrm{kg}^{-1}$ de MS) se encontrem acima da zona de transição tolerável para quantidade de extrato etéreo no ambiente ruminal, não foram suficientes para comprometer o desempenho dos novilhos. Segundo Kozloski (2009), a fermentação ruminal é inibida se o conteúdo de lipídios for superior a $70 \mathrm{~g} \mathrm{~kg}^{-1}$ matéria seca da dieta, pois o excesso de gordura forma uma cobertura hidrofóbica na célula bacteriana, que impede o seu metabolismo, ou sua adesão nas partículas da dieta. Oorre a existência de um efeito tóxico direto em que os ácidos graxos incorporariam a membrana bacteriana tornando-a fluível e permeável, o que aparentemente não aconteceu nesse experimento. Todavia, alguns pesquisadores preconizaram valores mais baixos, como, Mir, Mears e Mir (2001), que mencionaram que a inclusão de lipídios na dieta não deveria ultrapassar $60 \mathrm{~g}$ de extrato etéreo por $\mathrm{kg}$ matéria seca, por causar prejuízos na digestão dos alimentos e comprometer a ingestão de matéria seca (JENKINS, 1993).

Entre estudos que enfocaram o reflexo do extrato etéreo no desempenho bovino, citam-se os de Souza, Medeiros e Morais (2009), que não verificaram diferença $(\mathrm{P}>0,05)$ no consumo diário de matéria seca $\left(8,03 \mathrm{~kg} \operatorname{dia}^{-1}\right)$, utilizando como fonte de gordura, os grãos de soja moídos, com níveis de extrato etéreo de 31,5 e $72,8 \mathrm{~g} \mathrm{~kg}^{-1}$ de $\mathrm{MS}$, porém quando expressa em $100 \mathrm{~kg}$ de PV esta diferiu $(2,40$ vs. 2,25) $(\mathrm{P}<0,05)$.

Conforme Mertens (1994), o consumo de matéria seca em percentagem do peso vivo é melhor representado em animais que consomem alimentos fibrosos e que causam distensão ruminal, já que o efeito da dieta tem relação com o tamanho e capacidade do trato gastrintestinal. Em outras circunstâncias, o consumo de matéria seca em tamanho metabólico é melhor expresso para animais, que tem o consumo limitado fisiologicamente (MERTENS, 1994).

Diante dos resultados apresentados na Tabela 3, observa-se que os novilhos apresentaram consumo de matéria seca considerável para a categoria em estudo (110,31 g por unidade de tamanho metabólico), pois os resultados foram de acordo com os encontrados por Ezequiel et al. (2006), para animais com 24 meses de idade e raça semelhante. Os resultados induzem a afirmar que o fornecimento de dietas para obtenção de sobras entre 50 e $80 \mathrm{~g} \mathrm{~kg}^{-1}$ de matéria seca ofertada, não limitaram o consumo dos animais.

Em relação ao consumo de proteína bruta, expressos nas diferentes formas, também não se verificou diferença com a inclusão de borra na dieta ( $\mathrm{P}>0,05$; Tabela 3). Na formulação das dietas, pretendeu-se manter a proteína bruta semelhante entre os tratamentos, desse modo em função do consumo de matéria seca entre os novilhos serem similares, os resultados referentes ao consumo de proteína bruta tiveram mesmo comportamento (respectivamente, 1,36 kg, 15,49 g e 0,34 kg) para consumo de proteína diário, em relação ao tamanho metabólico e $100 \mathrm{~kg}$ de PV.

No presente trabalho, obteve-se consumo de proteína bruta, em percentual, levemente superior daquele pretendido na dieta (138,7 $\mathrm{g} \mathrm{kg}^{-1}$ de MS), verificando-se valor médio de $140,4 \mathrm{~g} \mathrm{~kg}^{-1}$ de MS. 
Para a variável eficiência de proteína bruta, também não foi observada diferença $(\mathrm{P}>0,05)$ com a inclusão de borra de soja na dieta, pois essa é calculada pela divisão entre o ganho médio diário e consumo de proteína bruta, que também não diferiram.

O consumo de proteína bruta pelos animais neste estudo foi similar aos resultados obtidos por Ezequiel et al. (2006) que encontraram média de 1,34 kg por dia. Entretanto, Shain et al. (1993) utilizaram na dieta de vacas leiteiras em lactação, uma mistura de lecitina e borra de soja, com níveis de 45 e $53 \mathrm{~g}$ de extrato etéreo $\mathrm{kg}^{-1}$ de matéria seca e obtiveram diferença no CPB em kg dia-1 e $100 \mathrm{~kg}$ de PV (4,63 kg dia ${ }^{-1} ; 0,77 \mathrm{~kg} 100^{-1}$ de PV e 4,75 kg dia ${ }^{1}$; $0,83 \mathrm{~kg} 100^{-1} \mathrm{de} \mathrm{PV}$, respectivamente), enquanto no presente trabalho observou-se consumo de proteína bruta inferior para o teor de extrato etéreo intermediário ao citado (para 47,3 g de extrato etéreo $\mathrm{kg}^{-1}$ de matéria seca), com valores de $1,34 \mathrm{~kg}$ $\mathrm{dia}^{-1}$ e $0,34 \mathrm{~kg} 100 \mathrm{~kg}^{-1}$ de PV.

No que se refere ao consumo de extrato etéreo da dieta, constatou-se comportamento linear para as diferentes formas com que essa fração lipídica foi expressa (Tabela 4). Resultado condizente com o teor de extrato etéreo na dieta, uma vez que não foi encontrada diferença no consumo de matéria seca. Pela interpretação da equação de regressão linear, pode-se verificar que a cada aumento de um grama na borra de soja, espera-se em média, que haja acréscimo de $6,1 \mathrm{~g}$ no consumo de extrato etéreo. À medida que a borra de soja foi adicionada na dieta, consequentemente, aumentou o teor de extrato etéreo na ração, procurando-se manter os níveis de gordura equidistantes. A ingestão de gordura foi próximo do ofertado na dieta (consumido 29,5; 49,2; 69,2; 90,0 e 111,5 g de EE kg-1 de MS; ofertado 29,$0 ; 47,3 ; 66,7 ; 86,8$ e 106,8 g de EE kg-1 de MS).

A inclusão de borra de soja proporcionou comportamento linear decrescente para eficiência lipídica (Tabela 4), sendo que para o aumento de um grama de borra de soja na dieta, foi observado em média redução de 0,031 na eficiência do extrato etéreo.

Em estudos com vacas de leite, Abel-Caines et al. (1998) utilizando mistura de lecitina de soja e borra de soja em diferentes proporções na dieta $(1,5: 1 ; 2,5: 1$ e $4: 1)$, correspondendo a 53; 52 e $51 \mathrm{~g}$ de $\mathrm{EE} \mathrm{kg}^{-1}$ de $\mathrm{MS}$, respectivamente, não observaram diferença no consumo de EE, que foi em média de $1,46 \mathrm{~kg} \mathrm{dia}^{-1}$ e $0,29 \mathrm{~kg} 100 \mathrm{~kg}^{-1}$ de PV. Portanto, os resultados encontrados no estudo em discussão foram inferiores aos divulgados por aqueles autores quando comparado com os mesmos teores de EE usados nas dietas experimentais.

A inclusão de borra de soja não influenciou $(\mathrm{P}>0,05)$ o consumo de energia digestível em Mcal pelos animais entre os tratamentos, porém quando essa foi expressa por unidade de tamanho metabólico e por $100 \mathrm{~kg}$ de peso a diferença ocorreu (Tabela 4). Apesar do consumo de matéria seca ter sido semelhante $(\mathrm{P}>0,05)$ essa diferença ocorreu em função do aumento de 19,3\% na densidade energética da dieta (NDT), do teor mais baixo ao mais alto de borra de soja na dieta.

Os resultados referentes aos consumos de fibras em detergente neutro e ácido apresentaram comportamento linear decrescente com inclusão de borra de soja na dieta ( $\mathrm{P}>0,05$; Tabela 5). Isso ocorreu em função do decréscimo de casca de soja, que possui elevado teor de FDN e do acréscimo de borra de soja que não possui FDN.

Através da interpretação das equações de regressão linear, verificou-se que a cada aumento de um grama na inclusão de borra de soja espera-se em média um decréscimo de $0,011 \mathrm{~kg} ; 0,122 \mathrm{~g}$ e 0,0027 $\mathrm{kg}$ no CFDN e 0,008 kg; 0,096 g e 0,0021 kg no CFDA, por dia, por unidade de tamanho metabólico e em $100 \mathrm{~kg}$ de peso vivo, respectivamente. A fração FDN é conhecida como componente da parede celular que melhor quantifica o preenchimento gastrintestinal. 
Tabela 5. Médias, coeficientes de variação e probabilidades dos consumos diários de fibras em detergente neutro e ácido por dia e eficiências das fibras na dieta de novilhos submetidos a níveis de inclusão de borra de soja.

\begin{tabular}{|c|c|c|c|c|c|c|c|}
\hline \multirow{2}{*}{ Variáveis } & \multicolumn{5}{|c|}{ Níveis de inclusão de borra de soja* } & \multirow{2}{*}{$\mathrm{CV}$} & \multirow{2}{*}{$\mathrm{P}>\mathrm{F}$} \\
\hline & 00 & 30 & 60 & 90 & 120 & & \\
\hline CFDN, kg dia ${ }^{-1}$ & 5,77 & 5,22 & 5,07 & 4,94 & 4,23 & 14,09 & 0.0011 \\
\hline CFDNTM, $\mathrm{g} \mathrm{kg}^{-1}$ peso vivo ${ }^{0,752}$ & 65,14 & 59,40 & 56,79 & 55,89 & 48,71 & 7,15 & 0.0001 \\
\hline CFDNPV, g $100 \mathrm{~kg}^{-1}$ peso vivo ${ }^{3}$ & 1,46 & 1,34 & 1,27 & 1,25 & 1,10 & 6,81 & 0.0001 \\
\hline EFDN, $\mathrm{kg}$ peso vivo $\mathrm{Kg}^{-1} \mathrm{FDN}^{4}$ & 0,276 & 0,299 & 0,315 & 0,303 & 0,349 & 10,99 & 0.0021 \\
\hline CFDA, $\mathrm{kg} \mathrm{dia}^{-15}$ & 3,91 & 3,52 & 3,39 & 3,26 & 2,73 & 13,97 & 0.0002 \\
\hline CFDATM, Mcal kg-1 peso vivo ${ }^{0,756}$ & 44,30 & 40,13 & 38,09 & 36,89 & 31,53 & 7,04 & 0.0001 \\
\hline CFDAPV, kg $100 \mathrm{~kg}^{-1}$ peso vivo ${ }^{7}$ & 0,996 & 0,905 & 0,855 & 0,831 & 0,714 & 6,73 & 0.0001 \\
\hline EFDA, kg peso vivo $\mathrm{kg}^{-1} \mathrm{FDA}^{8}$ & 0,406 & 0,443 & 0,470 & 0,461 & 0,538 & 10,86 & 0.0002 \\
\hline
\end{tabular}

* Na forma como o alimento é oferecido, $\mathrm{g} \mathrm{kg}^{-1}$

$\mathrm{BS}=$ teor de inclusão de borra de soja na dieta $\left(\mathrm{g} \mathrm{kg}^{-1}\right)$, na forma como o alimento é oferecido.

$\mathrm{CFDN}=$ consumo de fibra em detergente neutro; CFDNTM= consumo de fibra em detergente neutro por unidade de tamanho metabólico; CFDN/PV= consumo de fibra em detergente neutro em percentagem do peso vivo; EFDN= eficiência da fibra em detergente neutro; $\mathrm{CFDA}=$ consumo de fibra em detergente ácido; CFDATM= consumo de fibra em detergente ácido por unidade de tamanho metabólico; CFDAPV= consumo de fibra em detergente ácido em percentagem do peso vivo; EFDA= eficiência da fibra em detergente ácido;

${ }^{1} \mathrm{Y}=5,71-0,011 \mathrm{BS} ; \mathrm{R}^{2}=0,3207 ;{ }^{2} \mathrm{Y}=64,45-0,122 \mathrm{BS} ; \mathrm{R}^{2}=0,6280 ;{ }^{3} \mathrm{Y}=1,448-0,0027 \mathrm{BS} ; \mathrm{R}^{2}=0,6417 ;{ }^{4} \mathrm{Y}=0,279+0,0005 \mathrm{BS}$; $\mathrm{R}^{2}=0,2920 ;{ }^{5} \mathrm{Y}=3,89-0,008 \mathrm{BS} ; \mathrm{R}^{2}=0,3995 ;{ }^{6} \mathrm{Y}=43,94-0,096 \mathrm{BS} ; \mathrm{R}^{2}=0,7095 ;{ }^{7} \mathrm{Y}=0,998-0,0021 \mathrm{BS} ; \mathrm{R}^{2}=0,7215 ;{ }^{8} \mathrm{Y}=$ $0,407+0,0009 \mathrm{BS} ; \mathrm{R}^{2}=0,4019$.

Fonte: Elaboração dos autores.

Isso pode estar relacionado ao teor de lignina na dieta que também diminuiu com o aumento de inclusão de borra de soja, porque o teor de lignina do alimento é o principal responsável por regular a digestibilidade da FDN (NRC, 2001).

Baseado, principalmente, nos resultados apresentados por Conrad, Pratt and Hibbs (1964), Mertens (1987) propôs um modelo para estimar o consumo voluntário de vacas em lactação. Segundo este modelo, dietas que apresentam elevado teor de energia, tem seu consumo limitado pelo atendimento das exigências energéticas do animal. Entretanto, dietas com baixo teor energético tem o consumo limitado pela capacidade física de ingestão ou enchimento ruminal. Assim, Mertens (1994) sugeriu a concentração de fibra em detergente neutro na dieta como limitante de consumo de matéria seca, visto que essa é inversamente relacionada ao teor energético e que melhor representa as características dos alimentos em ocupar espaço.

Mediante dessas afirmações Mertens (1987) sugeriu, nas situações em que o consumo seja limitado pela capacidade física, o consumo de FDN mantenha-se próximo de $12,0( \pm 1,0) \mathrm{g} \mathrm{kg}^{-1}$ de peso vivo. Embora esse valor tenha sido citado para vacas em lactação, muitos pesquisadores afirmam que ele pode ser relacionado com bovinos em crescimento.

Perante dessas informações, verificou-se que a dieta com $120 \mathrm{~g}$ de borra de soja por kg de matéria seca na dieta está dentro do valor sugerido por Mertens (1987) para o consumo de FDN, com 11,0 g $\mathrm{kg}^{-1}$ de PV. Logo, o consumo da referida fração não prejudicou o consumo de matéria seca dos novilhos em nenhum dos teores de inclusão de borra de soja. Nesse contexto, a borra de soja dificilmente poderá limitar o consumo via FDN, pois esse ingrediente apresenta em sua composição bromatológica zero $\%$ de fibra bruta.

Tanto para a eficiência de fibra em detergente neutro e ácido em ser transformada em ganho de peso vivo, foram observados comportamentos lineares decrescentes $(\mathrm{P}<0,05$; Tabela 5). Como 
essas frações são resultados da divisão do ganho de peso vivo dos animais $(\mathrm{P}>0,05)$ pelo consumo das referidas frações $(\mathrm{P}<0,05)$, a conclusão é coerente, portanto, para o aumento de uma grama na inclusão de borra de soja na dieta espera-se em média acréscimo de 0,0005 e 0,0009 na eficiência de transformação da fibra em detergente neutro e ácido em ganho de peso vivo, respectivamente.

Analisando os resultados apresentados na Tabela 6 , constata-se que a inclusão de borra de soja na dieta não promoveu alteração $(\mathrm{P}>0,05)$ no ganho médio diário dos novilhos, com média de $1,542 \mathrm{~kg}$. Essa semelhança proporcionou peso final similar $(457,92$ $\mathrm{kg}$; $\mathrm{P}>0,05)$ após 84 dias de período experimental ao atingirem adequada cobertura de gordura para comercialização. O peso final e ganho médio diário atingido são consideráveis para categoria em estudo, pois são animais oriundos de desmame precoce (6090 dias) e recriados em sistema extensivo em campo nativo infestado por capim anoni (Eragrostis plana) que apresenta baixa qualidade durante a maior parte do ano. Esse desempenho é reflexo do consumo de matéria seca e energia digestível, sendo que essas variáveis não diferiram entre os tratamentos estudados $(\mathrm{P}>0,05)$.

Tabela 6. Médias, coeficientes de variação e probabilidades de pesos inicial e final, ganho de peso médio diário, escore corporal inicial e final, ganho de condição corporal, conversão alimentar por dia de novilhos submetidos a níveis de inclusão de borra de soja.

\begin{tabular}{|c|c|c|c|c|c|c|c|}
\hline \multirow{2}{*}{ Variáveis } & \multicolumn{5}{|c|}{ Níveis de inclusão de borra de soja* } & \multirow{2}{*}{$\mathrm{CV}$} & \multirow{2}{*}{$\mathrm{P}>\mathrm{F}$} \\
\hline & 0,0 & 3,0 & 6,0 & 9,0 & 12,0 & & \\
\hline Peso inicial, $\mathrm{kg}$ & 330,3 & 324,5 & 329,0 & 334,0 & 323,7 & 14,09 & 0,9947 \\
\hline Peso final, kg & 464,2 & 455,3 & 462,6 & 459,5 & 448,0 & 13,14 & 0,9902 \\
\hline Ganho de peso médio diário, $\mathrm{kg} \mathrm{dia}^{-1}$ & 1,594 & 1,557 & 1,590 & 1,493 & 1,479 & 14,59 & 0,8431 \\
\hline Escore corporal inicial, pontos ${ }^{* *}$ & 2,93 & 2,83 & 2,75 & 2,91 & 2,85 & 4,33 & 0,1119 \\
\hline Escore corporal inicial, pontos ${ }^{* *}$ & 4,13 & 4,01 & 4,08 & 4,03 & 4,01 & 4,24 & 0,7203 \\
\hline Ganho de condição corporal, pontos dia $^{-1}{ }^{\text {** }}$ & 0,0142 & 0,0140 & 0,0158 & 0,0132 & 0,0138 & 14,10 & 0,2809 \\
\hline Conversão alimentar, $\mathrm{kg} \mathrm{MS} \mathrm{kg}^{-1}$ peso vivo & 6,53 & 6,23 & 6,18 & 6,66 & 6,18 & 8,82 & 0,4577 \\
\hline
\end{tabular}

* Na forma como o alimento é oferecido, $\mathrm{g} \mathrm{kg}^{-1}$

** Escala variando de 1 a 5 , onde $1=$ muito magro e $5=$ muito gordo.

Fonte: Elaboração dos autores.

Aferri et al. (2005) ao trabalharem com diferentes fontes de lipídios na dieta de novilhos aos 14 meses de idade (controle, caroço de algodão e sais de ácidos graxos de cálcio) não observaram diferença no GMD $(1,16 \mathrm{~kg})$ e no peso final (434 $\mathrm{kg}$ ), enquanto que Souza, Medeiros e Morais (2009) trabalharam com baixo (31,5 g EE) e alto $(72,8 \mathrm{~g}$ $\mathrm{EE}$ ) teor de gordura por $\mathrm{kg}$ de matéria seca, na dieta de tourinhos aos 10 meses de idade e obtiveram GMD semelhante aos encontrados neste estudo, de 1,487 e $1,511 \mathrm{~kg} \mathrm{dia}^{-1}$ e peso vivo final $461 \mathrm{e}$ $462 \mathrm{~kg}$, respectivamente. Os resultados obtidos neste estudo foram semelhantes aos reportados por Felton e Kerley (2004) que ao avaliarem uma dieta convencional (48 g EE) e com 16\% de grãos de soja (81 g EE), na ração de novilhos cruzados em confinamento verificaram GMD de 1,55 vs $1,40 \mathrm{~kg}$ dia $^{-1}$, respectivamente.

Ainclusãodeborra de soja na dieta não influenciou $(\mathrm{P}>0,05)$ o escore de condição corporal final dos animais, com média de 4,04 pontos, classificando os novilhos como gordos. Esse resultado é reflexo do ganho de escore de condição corporal, que não diferiu durante o período experimental. 
Não houve diferença $(\mathrm{P}>0,05)$ na conversão alimentar com aumento da inclusão de borra de soja na dieta (Tabela 6). A mensuração da conversão alimentar é importante, pois quanto menor for menor o seu valor mais nutritiva será a dieta, o que oportunizará ao animal ser mais eficiente, isto é, necessitará de menor quantidade de matéria seca para obter um $\mathrm{kg}$ de peso corporal.

Resultados de ausência de diferença na conversão alimentar são concordantes com os obtidos por Restle, Keplin e Vaz (1997); Aferri et al. (2005) e Jorge, Zeoula e Prado (2009), cujo valores foram de 8,73; 8,09 e 12,9 kg MS kg-1 PV, respectivamente, os quais estudaram diferentes fontes de gordura na dieta.

\section{Conclusão}

O uso da borra de soja é uma alternativa viável até o limite de $120 \mathrm{~g}$ por quilograma de alimento na forma como foi ofertado na dieta de bovinos confinados.

\section{Referências}

ABEL-CAINES, S. F.; GRANT, R. J.; MORRISON, M. Effect of soybean hulls, soy lecithin, and soapstock mixtures on ruminal fermentation and milk composition in dairy cows. Journal Dairy Science, Champaign, v. 81, n. 2, p. 462-470, 1998.

AFERRI, G.; LEME, P. R.; SILVA, S. L.; PUTRINO, S. M.; PEREIRA, A. S. C. Desempenho e características de carcaça de novilhos alimentados com dietas contendo diferentes fontes de lipídios. Revista Brasileira de Zootecnia, Viçosa, MG, v. 34, n. 5, p. 1651-1658, 2005.

CONRAD, H. R.; PRATT, A. D.; HIBBS, J. W. Regulation of feed intake in dairy cows. I. Change in importance of physical and physiological factors ith increasing digestility. Journal of Dairy Science, Champaign, v. 47, n. 1, p. 54-62, 1964.

EZEQUIEL, J. M. B.; CRUZ e SILVA, O. G. da; GALATI, R. L.; WATANABE, P. H.; BIAGIOLI, B.; FATURI, C. Desempenho de novilhos Nelore alimentados com casca de soja ou farelo de gérmen de milho em substituição parcial ao milho moído. Revista Brasileira de Zootecnia, Viçosa, MG, v. 35, n. 2, p. 569-575, 2006.
FELTON, E. E. D.; KERLEY, M. S. Performance and carcass quality of steers fed different sources of dietary fat. Journal of Animal Science, Champaign, v. 82, n. 6, p. 1794-1805, 2004.

JENKINS, T. C. Lipid metabolism in the rumen. Journal of Dairy Science, Champaign, v. 76, n. 12, p. 3851-3863, 1993.

JORGE, J. R. V.; ZEOULA, L. M.; PRADO, I. N. Gordura protegida sobre o desempenho, carcaça e composição química da carne de novilhos Holandês. Archivos de Zootecnia, Córdoba, v. 58, n. 223, p. 371-382, 2009.

KOZLOSKI, G. V. Bioquímica dos ruminantes. 2. ed. rev. e ampl. Santa Maria: Ed. da UFSM, 2009. 216 p.

LOWAMAN, B. G.; SCOTT, N.; SOMERVILLE, S. Condition scoring beef catle. Edinburgh: East of Scotland College of Agriculture, 1973. 8 p. (Bulletin, 6).

MERTENS, D. R. Predicting intake and digestibility using mathematical models of ruminal function. Journal of Animal Science, Champaign, v. 64, n. 5, p. 1548-1558, 1987.

MERTENS, D. R. Regulation of forage intake. In: GEORGE, C.; FAHEY, J. (Ed.). Forage quality, evaluation and utilization. Madison, W.I.: American Society of Agronomy, Crop Science of America, Soil Science of America, 1994. p. 450-493.

MIR, P. S.; MEARS, G. L.; MIR, Z. Vegetable oil in beef catle diets. In: BEAUCHEMIN, K. A.; CREWS, D. H. (Ed.) Advances in beef cattle science. Lethbridge: Lethbridge Research Centre, 2001. v.1, p. 88-104.

NATIONAL RESEARCH COUNCIL - NRC. Nutrients requirements of beef cattle. Seventh Revised Edition, Washington, DC, 2001. $232 \mathrm{p}$.

OBICI, S.; FENG, Z. H.; MORGAN, K.; STEIN, D.; KARKANIAS, G.; ROSSETI, L. Central administration of oleic acid inhibits glucose production and food intake. Diabetes, Alexandria, v. 51, n. 2, p. 271-275, 2002.

RESTLE, J.; KEPLIN, L. A. da S.; VAZ. F. N. Desempenho em confinamento de novilhos Charolês terminados com diferentes pesos. Pesquisa Agropecuária Brasileira, Brasília, v. 32, n. 8, p. 857-860, 1997.

STATISTICAL ANALYSIS SYSTEM INSTITUTE SAS. Institute Incorporation. SAS Language Reference. Version 6. Cary, NC: SAS institute, 2001. 1042 p.

SHAIN, D. H.; SINDT, M. H.; GRANT, R. J.; KLOPFENSTEIN, T. J.; STOCK, R. A. Effect of a soybean hull:soy lecithin:soapstock mixture on ruminal digestion and performance of growing beef calves and lactating dairy cattle. Journal Animal Science, Champaign, v. 71, n. 5, p. 1266-1275, 1993. 
SOUZA, A. R. D.; MEDEIROS, S. R. de; MORAIS, M. da G. Dieta com alto teor de gordura e desempenho de grupos genéticos diferentes em confinamento. Pesquisa Agropecuária Brasileira, Brasília, v. 44, n. 7, p. 746-753, 2009.

VAN SOEST, P. J. Nutrional ecology of the ruminant. 2. ed. Ithaca, New York: Cornell University Press, 1994. $476 \mathrm{p}$.
WEISS, W. P.; CONRAD, H. R.; PIERRE, N. R. St. A theoreticall y based model for predicting total digestible nutrient values of forages and concentrates. Animal Feed Science and Technology, Amsterdam, v. 39, n. 1-2, p. 95-110, 1992. 